\title{
Molecular Basis of TRPA1 Regulation in Nociceptive Neurons.
} A Review

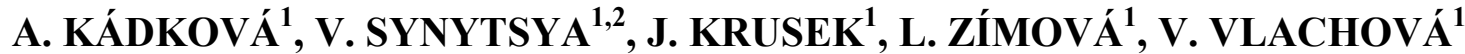 \\ ${ }^{1}$ Department of Cellular Neurophysiology, Institute of Physiology of the Czech Academy of \\ Sciences, Prague, Czech Republic, ${ }^{2}$ Department of Physical and Macromolecular Chemistry, \\ Faculty of Science, Charles University in Prague, Prague, Czech Republic
}

Received November 8, 2016

Accepted February 27, 2017

\section{Summary}

Transient receptor potential A1 (TRPA1) is an excitatory ion channel that functions as a cellular sensor, detecting a wide range of proalgesic agents such as environmental irritants and endogenous products of inflammation and oxidative stress. Topical application of TRPA1 agonists produces an acute nociceptive response through peripheral release of neuropeptides, purines and other transmitters from activated sensory nerve endings. This, in turn, further regulates TRPA1 activity downstream of G-protein and phospholipase C-coupled signaling cascades. Despite the important physiological relevance of such regulation leading to nociceptor sensitization and consequent pain hypersensitivity, the specific domains through which TRPA1 undergoes post-translational modifications that affect its activation properties are yet to be determined at a molecular level. This review aims at providing an account of our current knowledge on molecular basis of regulation by neuronal inflammatory signaling pathways that converge on the TRPA1 channel protein and through modification of its specific residues influence the extent to which this channel may contribute to pain.

\section{Key words}

Transient receptor potential ankyrin 1 • Bradykinin • Structurefunction - Nociception - Post-translational modifications • Signaling pathways

\section{Corresponding authors}

A. Kádková and V. Vlachová, Department of Cellular Neurophysiology, Institute of Physiology AS CR, Videnska 1083, 14220 Prague 4, Czech Republic. Fax. 420-29644-2488. E-mail: Anna.Kadkova@fgu.cas.cz or Viktorie.Vlachova@fgu.cas.cz

\section{Introduction}

The Transient Receptor Potential Ankyrin 1 (TRPA1) channel, originally called ANKTM1 (Story et al. 2003), is an ion channel dominantly expressed in a subset of nociceptive somatosensory neurons where it acts as a polymodal sensor for diverse physical and chemical stimuli of extracellular or intracellular origin. This channel is characterized by a marked activating agent promiscuity towards painful or potentially harming stimuli, including natural and exogenous electrophilic compounds, ultraviolet radiation, oxygen, extreme temperatures, chemical irritants and endogenous inflammatory mediators (Nilius et al. 2011, Nilius et al. 2012, Laursen et al. 2014, Zygmunt and Hogestatt 2014, Chen and Hackos 2015, Viana 2016). Studies using TRPA1 knock-out mice and specific antagonists have linked the function of TRPAl to the regulation of temperature perception, inflammation, mechanosensation, pain, itching, but also the homeostatic balance between the nociceptive and the immune system (Bandell et al. 2004, Kwan et al. 2006, Viana 2016). In peptidergic nociceptors, TRPA1 is extensively co-expressed with the structurally related vanilloid receptor subtype 1 channel TRPV1. These two channels functionally interact and share multiple and overlapping signaling pathways that lead to their post-translational modifications regulating their activity and thus the nociceptor excitability (Story et al. 2003, Bandell et al. 2004, Jordt et al. 2004, Staruschenko et al. 2010). A clear demonstration of functional interaction between TRPV1 and TRPA1 in the bradykinin signaling pathways was first 
shown in 2006 when the TRPA1-deficient mice were generated (Bautista et al. 2006). The authors demonstrated that the magnitude of bradykinin-evoked responses in trigeminal neurons from control mice correlated with the size of TRPA1-mediated responses induced by the selective agonist allyl isothiocyanate but not with those induced by the specific TRPV1 agonist capsaicin. The bradykinin-evoked responses were significantly attenuated and the correlation was completely lost in both TRPA1and TRPV1-deficient neurons.

The activation of TRPA1 at nerve terminals results in membrane depolarization mainly due to $\mathrm{Na}^{+}$influx and induces a local calcium influx through the channel which further releases neuropeptides such as calcitonin gene-related peptide (CGRP), substance $\mathrm{P}$, or neurokinin A from large dense-core vesicles via $\mathrm{Ca}^{2+}$-dependent exocytosis (Gustavsson et al. 2012). The presence of neuropeptides causes a further amplification of nociception, recruitment of immune cells, vasodilatation and neurogenic inflammation (Geppetti et al. 2008). Accordingly, TRPA1 has been functionally linked to a number of chronic pain conditions associated with inflammation, including visceral pain, arthritic pain, cancer pain, and migraine. It is generally assumed that proinflammatory agents released at the site of injury, such as prostaglandins, bradykinin, serotonin and extracellular proteases, modulate TRPA1 via G-protein-coupled receptors and phospholipase C-coupled signaling cascades (Fig. 1). These mediators can directly activate TRPA1 (Taylor-Clark et al. 2008) or stimulate protein kinase A (PKA), protein kinase C (PKC), and phospholipase $\mathrm{C}$ (PLC) pathways to induce phosphorylation of TRPA1 (Dai et al. 2007, Wang et al. 2008a, Andrade et al. 2012, Petho and Reeh 2012). Phosphorylation, in turn, significantly affects the activation threshold of TRPA1, rendering nociceptors more sensitive to noxious stimulation. The putative roles of the PKA- and PLC-dependent signaling pathways in TRPA1-mediated nociception have recently been very well reviewed by previous authors (Andrade et al. 2012, Nilius et al. 2012, Bautista et al. 2013, Zygmunt and Hogestatt 2014, Viana 2016). Despite the presumed physiological importance of TRPA1 post-translational modifications, little is known about the specific domains and residues through which the TRPA1 protein undergoes conformational changes that affect the activation properties of this channel (Voolstra and Huber 2014). This review aims at providing an overview of the currently available results of site-directed mutagenesis studies on TRPA1 and summarizes the data on the functionally important amino acids which are involved in TRPA1 activation and may represent the residues through which this channel is regulated by phosphorylation or other post-translational modifications.

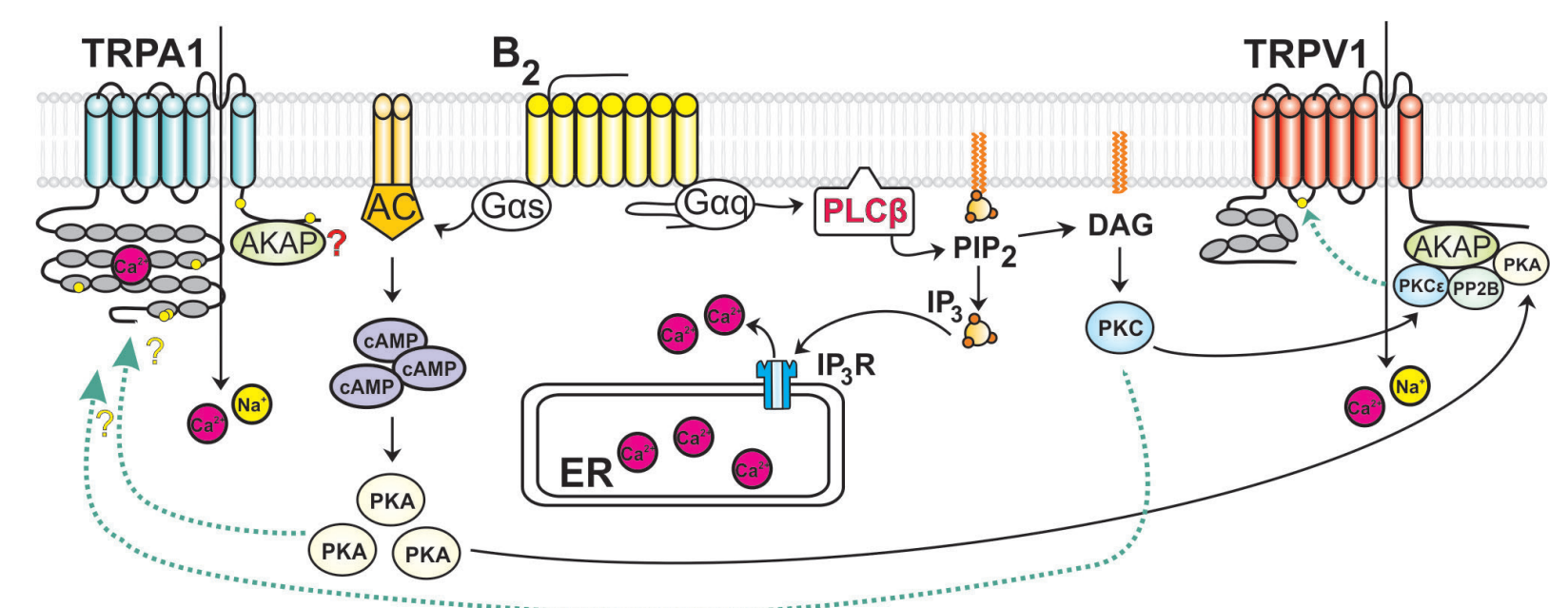

Fig. 1. Different but interconnected signaling pathways contribute to the sensitization of TRPA1 (adapted from Andrade et al. 2012). The binding of an agonist to the bradykinin receptor $2\left(B_{2}\right)$ triggers phospholipase C $\beta$ (PLC $\beta$ ) through Gaq protein. PLC $\beta$ cleaves phosphatidylinositol-4,5-bisphosphate $\left(\mathrm{PIP}_{2}\right)$ into diacylglycerol (DAG) and inositol triphosphate $\left(\mathrm{IP}_{3}\right)$. Ca ${ }^{2+}$ release from the endoplasmic reticulum (ER) induced by binding of $\mathrm{IP}_{3}$ to the inositol triphosphate receptor $\left(\mathrm{IP}_{3} \mathrm{R}\right)$ probably directly sensitizes TRPA1. The activation of protein kinase $C \varepsilon(P K C \varepsilon)$ by DAG results into the binding of the kinase to the anchoring protein AKAP79/150 (AKAP) bound to the C-terminus of TRPV1 and into phosphorylation of TRPV1 which, in turn, sensitizes this channel to an agonist, promoting $\mathrm{Ca}^{2+}$ influx. AKAP79/150 binds also to TRPA1 (Zhang et al. 2008). The $B_{2}$ receptor can also stimulate the Gas protein that activates the synthesis of cyclic adenosine monophosphate (CAMP) by adenylate cyclase (AC). The activation of protein kinase A (PKA) by cAMP or the activation of protein kinase C (PKC) by DAG sensitizes TRPA1 (putative phosphorylatable serine/threonine residues are indicated as yellow circles). In addition, PKA can also bind to the AKAP79/150 protein on TRPV1 together with PKC $\varepsilon$ and the phosphatase calcineurin (PP2B) to either phosphorylate or dephosphorylate the receptor at serine $\mathrm{S} 502$, depicted as a yellow circle. 


\section{Structural characteristics of TRPA1}

All TRP channels share a similar general topology consisting of four pore-forming subunits, each of which contains six transmembrane segments (S1-S6) comprised of a sensor module S1-S4 and an ion conduction pore-forming region S5-S6. Both amino- and carboxyl-terminal domains are located cytoplasmically (Owsianik et al. 2006). Among mammalian TRP channels, TRPA1 is unique in bearing an extensive cytoplasmic amino terminus (720 of 1119 amino acids), comprised of a prominent ankyrin repeat domain (ARD; amino acids 1-639) and a linker (amino acids 640-720) consisting of a $\beta$-hairpin loop followed by two $\alpha$-helices and the pre-S1 helix that connects ARD with the first transmembrane segment (Cvetkov et al. 2011, Brewster and Gaudet 2015, Paulsen et al. 2015). The proximal C-terminus is divided into a TRP-like domain, a putative $\beta$-sheet and a long coiled-coil. Atomic resolution structures of the distal cytoplasmic termini have not been resolved yet. Recent advances in electron cryo-microscopy allowed determining the first atomiclevel structure of human TRPA1 captured in a closedpore conformation (Paulsen et al. 2015). Also recently, a unified model of gating mechanism based on a comparative sequence analysis of the transmembrane regions from almost three thousand different TRP proteins has been proposed (Palovcak et al. 2015). Combined with the known structures of three related channels, TRPV1, TRPV2 and TRPV6 in open, closed or desensitized states, these findings offer new approaches to the further understanding of the TRPA1 channel and the general principles of TRP channel functioning (Cao et al. 2013, Liao et al. 2013, Gao et al. 2016, Huynh et al. 2016, Saotome et al. 2016, Zubcevic et al. 2016). These new structures enable precise molecular modelling of different activation states of TRPA1 and allow to overlay the available information obtained from point mutagenesis experiments on an accurate spatial model (Brewster and Gaudet 2015).

\section{Activation, potentiation and inactivation of TRPA1}

TRPA1 constitutes a target for a range of pungent and irritating chemical substances of endogenous origin (reviewed in Laursen et al. 2014, Zygmunt and Hogestatt 2014). Algogenic and pro-inflammatory agents, such as prostaglandins, bradykinin, histamine, and trypsin, acting on $\mathrm{G}$ protein-coupled receptors, stimulate the production of intracellular mediators that directly or indirectly activate TRPA1. Oxygen, reactive oxygen species and reactive nitrogen species directly activate TRPA1. Molecular mechanism underlying $\mathrm{O}_{2}$-sensing involves prolyl hydroxylation of conserved proline P394 within the $\mathrm{N}$-terminal ankyrin repeat 10 and oxidation of cysteines C633 and/or C856 (Miyamoto et al. 2009, Takahashi et al. 2011).

The origin of the exogenous chemicals activating TRPA1 is either natural, or synthetic. Pungent compounds from cinnamon (cinnamaldehyde), horseradish and wasabi (allyl isothiocyanate) or garlic (allicin) belong to the first aforementioned group, whereas some synthetic drugs (general anesthetics isoflurane or propofol) and acrolein, an irritant in tear gas and vehicle exhaust fumes, are only a few examples from the second group (recent comprehensive reviews - Nilius et al. 2012, Zygmunt and Hogestatt 2014, Viana 2016). From chemical point of view, modulators of TRPA1 can be both electrophilic and non-electrophilic compounds. The electrophilic activators bind covalently to reactive cysteines C621, C641, C665 within the N-terminus of TRPA1. Of these, the most important is cysteine C621 that possesses an exceptionally high reactivity imparted by the neighboring lysine residue K620 (Bahia et al. 2016). The variability of TRPA1 covalent agonists is enormous and the reactions include nitrosylation (nitric oxide), sulfhydration (sulfane), forming of a disulphide bond (hydrogen peroxide) and alkylation. The electrophiles alkylate TRPA1 by the mechanism known as the Michael addition. The unsaturated bond of $\alpha, \beta$-unsaturated aldehydes such as acrolein, cinnamaldehyde or allyl isothiocyanate is attacked by a nucleophilic mercapto-group of a cysteine or an amino group of a lysine (Hinman et al. 2006, Macpherson et al. 2007).

Probably the most important physiological activators and modulators of TRPA1 are calcium ions, which enter through the channel or are released from internal stores and, depending on the activation state, dynamically control the critical properties of the channel (Story et al. 2003, Nagata et al. 2005, Wang et al. 2008b, Nilius et al. 2011). Although TRPA1 is often referred to as nonselective cation channel, its favoring of calcium is noticeable. Its selectivity for mono- and divalent cations is determined by a selectivity filter formed by the sequence glycine-aspartate-isoleucine $\left({ }^{914} \mathrm{GDI}^{916}\right)$, located in the loop between the two pore helices (Wang et al. 
2008b). Combined patch-clamp and Fura-2 fluorescence measurements revealed that the fraction of TRPA1 inward current that is carried by $\mathrm{Ca}^{2+}$ is much higher than in the case of a non-selective channel (Karashima et al. 2010). This phenomenon probably arises from a partial block $(\sim 35 \%)$ of the monovalent cation current caused by binding of $\mathrm{Ca}^{2+}$ in the lumen of the pore. The intracellular $\mathrm{Ca}^{2+}$ influences the most important properties of the channel: conductance, ion selectivity and opening probability (Cavanaugh et al. 2008, Karashima et al. 2010, Nilius et al. 2011). Moreover, the increase of the TRPA1 surface expression level, which can be induced by an agonist exposure, is not observed in $\mathrm{Ca}^{2+}$-free solution suggesting the role of calcium ions in TRPA1 membrane trafficking (Schmidt et al. 2009). The agonist- and voltage-induced TRPA1 currents are strongly amplified by the intracellular $\mathrm{Ca}^{2+}$. The potentiation of TRPA1 currents is followed by an inactivation (desensitization), which is almost complete and irreversible and both these processes can be accelerated by the increasing concentration of $\mathrm{Ca}^{2+}$. The potentiation and the inactivation are independent processes. The elevation of intracellular $\mathrm{Ca}^{2+}$ causes the TRPA1 potentiation, whereas the extracellular $\mathrm{Ca}^{2+}$ are required for the inactivation (Wang et al. 2008b). However, the exact molecular mechanisms of these processes have not yet been fully understood. The negatively charged residues within a loop between the N-terminal ankyrin repeats 12 and 13 have been thought to be a $\mathrm{Ca}^{2+}$-binding site in TRPA1. However, the role of this so-called EF-hand in both $\mathrm{Ca}^{2+}$-dependent potentiation and inactivation has been disputed by several studies (Wang et al. 2008b, Sura et al. 2012). Thus, further studies are needed to find other calcium-binding sites within the TRPA1 protein. TRPA1 is activated by intracellular $\mathrm{Ca}^{2+}$ ions at micromolar concentrations and the activation mechanism does not depend on calmodulin or other $\mathrm{Ca}^{2+}$-binding proteins, neither it depends on the interaction of TRPA1 with phosphatidylinositol 4,5-bisphosphate ( $\mathrm{PIP}_{2}$ ) (Doerner et al. 2007, Zurborg et al. 2007). Although several studies supported the role of $\mathrm{PIP}_{2}$ in TRPA1 modulation (Rohacs 2009), the newly developed methods for $\mathrm{PIP}_{2}$ level manipulation indicate that agonist responses of TRPA1 are probably not significantly influenced by changes in $\mathrm{PIP}_{2}$ levels (Wang et al. 2008b, Nilius et al. 2011).

\section{Putative phosphorylation pathways involved in TRPA1-mediated bradykinin-induced nociception}

Bradykinin is one of the most potent pronociceptive mediators produced under inflammation. Two types of G protein-coupled receptors (GPCR) for bradykinin have been characterized in nociceptive neurons, $B_{1}$ and $B_{2}$, both signaling through $G_{q / 11}$ (in Fig. 1 shown as Gaq subunit) to increase intracellular concentrations of calcium (Petho and Reeh 2012). While $\mathrm{B}_{2}$ is widely expressed in many tissues including the nervous system, $B_{1}$ protein expression is rapidly increased under tissue injury or inflammation (Chen and Johnson 2007). Stimulation of $B_{1}$ or $B_{2}$ by bradykinin can initiate either the phospholipase $\mathrm{C}$ (PLC) pathway or activation of adenylate cyclase (AC) to produce cyclic adenosine monophosphate (cAMP), which further activates protein kinase A (PKA) (Fig. 1). After the PLC pathway is initiated, PLC breaks down $\mathrm{PIP}_{2}$ into diacylglycerol (DAG) and inositol triphosphate $\left(\mathrm{IP}_{3}\right)$. Diacylglycerol either activates protein kinase C (PKC) or it can be converted into polyunsaturated fatty acids, such as arachidonic acid, by DAG lipase. $\mathrm{IP}_{3}$, in turn, induces release of calcium ions from the intracellular stores in endoplasmic reticulum (Bandell et al. 2004, Mizumura et al. 2009, Andrade et al. 2012). The influx of extracellular calcium ions together with $\mathrm{Ca}^{2+}$ released from intracellular stores directly activate TRPA1 (Doerner et al. 2007, Zurborg et al. 2007).

In nociceptive neurons, the regulation of TRPV1 by protein kinases PKA and PKC and the phosphatase calcineurin strongly depends on an interaction with the A kinase anchoring protein AKAP79/150, which enables the formation of a signaling complex between these enzymes and TRPV1 and thus a dynamic modulation of the channel (balancing phosphorylation and dephosphorylation). In addition, binding of AKAP79/150 is necessary for membrane trafficking of TRPV1 (Zhang et al. 2008). A similar mechanism of sensitization by protein kinases can be predicted also in TRPA1 as the interaction between AKAP79/150 and TRPA1 has been confirmed by co-immunoprecipitation experiments (Zhang et al. 2008). The primary sequence of human TRPA1 clearly predicts several phosphorylation sites for PKA kinase (Table 1) and potentiation of agonist-induced responses by bradykinin can be inhibited by PKA and PLC inhibitors or mimicked by PLC or PKA activators (Wang et al. 2008a). Several putative 
PKC phosphorylation sites are predicted from the primary sequence of TRPA1, though their functional roles have not been systematically studied. From published experiments in which the PLC or PKA activators and inhibitors were used by several authors, it is not always clear whether the effects on TRPA1 reflect phosphorylation because calcium ions were usually present in extracellular solution and their direct effect cannot be excluded. In addition, TRPA1-mediated responses gradually increase during prolonged application of agonist and this intrinsic sensitization precludes from clearly differentiating the effects of kinase modulators (Meents et al. 2016). The situation is further complicated by the fact that the choice of the expression system for TRPA1 has been shown to be critical as the channel is constitutively activated at physiological membrane potentials, leading to a massive increase in cellular $\mathrm{Ca}^{2+}$ (Karashima et al. 2008).

Figure 2 shows how heterologous expression of TRPA1 in a neuronal cell line may influence cellular responses to membrane depolarization. To illustrate this point, for the purpose of this review, we measured responses from cells that are derived from rat dorsal root ganglion neurons $\mathrm{F} 11$ as in vitro model of native peripheral sensory neurons (Francel et al. 1987). This cell line lacks TRPA1 and exhibits a specific combination of action potential properties and cell markers, including those for nociceptive sensory neurons (Vetter and Lewis 2010, Yin et al. 2016): the F11 cells endogenously express voltage gated $\mathrm{K}^{+}$and $\mathrm{Na}^{+}$channels (particularly $\mathrm{K}_{\mathrm{V}}$ 11.1, $\mathrm{Na}_{\mathrm{V}} 1.6$ and $\mathrm{Na}_{\mathrm{V}} 1.7$ ), and many other ion channels and receptors with recognized roles in nociception. We used whole-cell patch clamp technique exactly as described in (Hynkova et al. 2016). The cells repeatedly stimulated with depolarizing pulses from $-60 \mathrm{mV}$ to $+60 \mathrm{mV}$ exhibited inward currents, which are typical for voltage-gated $\mathrm{Na}^{+}$channels (Fig. 2A). Then, we transiently expressed TRPA1 in F11 cells using a standard transfection method as we previously described in (Sura et al. 2012) and (Hynkova et al. 2016). In contrast to naïve cells, when TRPA1 were relatively more expressed in $\mathrm{F} 11$, the voltage-gated $\mathrm{Na}^{+}$currents were fully dampened (Fig. 2B, C). Thus, the activation of TRPA1 by depolarization, or its presence itself, affects cellular excitability to a large extent.
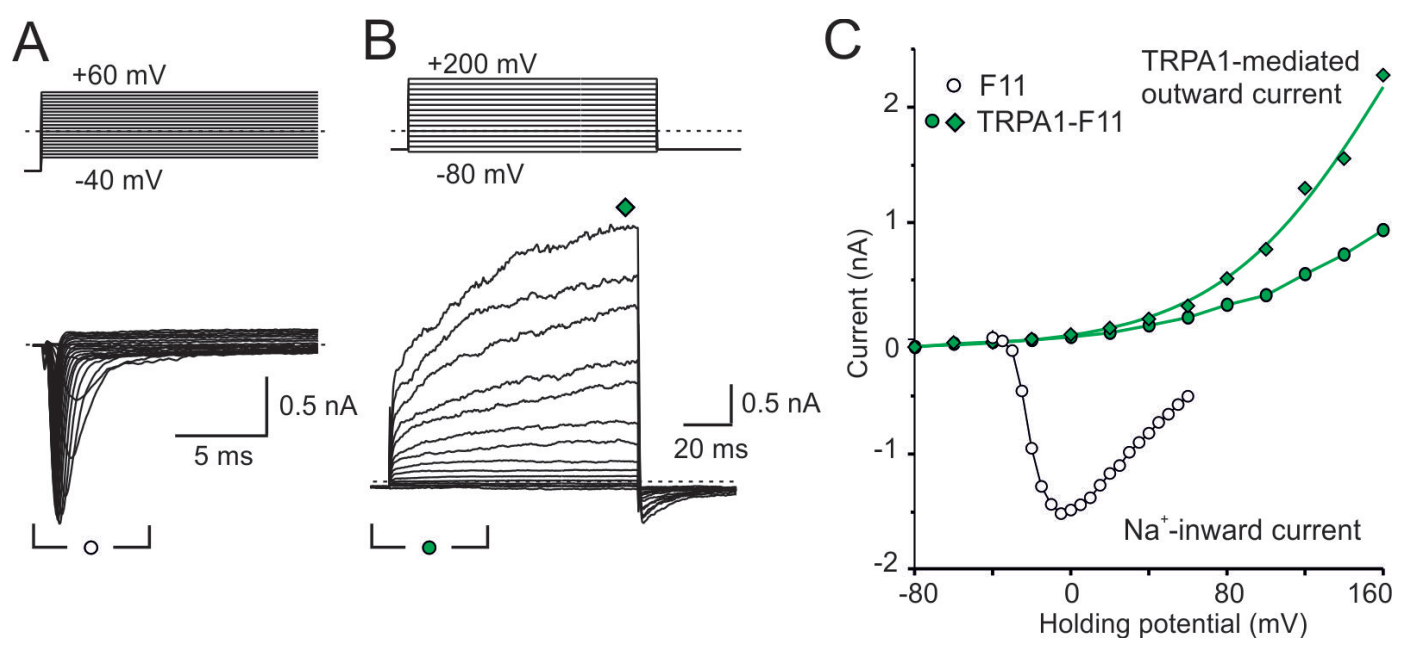

Fig. 2. Transfection of $F 11$ cells with TRPA1 produces large outward currents upon depolarizing steps and reduces inward currents at negative membrane potentials. (A), Untransfected F11 cells displayed characteristic voltage-gated sodium channels in depolarizing step recordings (depolarizing pulses from $-40 \mathrm{mV}$ to $+60 \mathrm{mV}$, voltage step protocol indicated above). (B) TRPA1 transfected cells stimulated by depolarizing pulses from $-80 \mathrm{mV}$ to $+200 \mathrm{mV}$ (voltage step protocol indicated above). The voltage-gated $\mathrm{Na}^{+}$currents were fully dampened. (C) Current-voltage relationship constructed from A and B at the times indicated by symbols: naïve F11, inward currents (open circle), TRPA1-expressing F11, inward currents (green circle), outward currents (green diamond). Whole-cell membrane currents were recorded using the extracellular bath solution containing $160 \mathrm{mM} \mathrm{NaCl}, 2.5 \mathrm{mM} \mathrm{KCl}, 1 \mathrm{mM} \mathrm{CaCl}, 2 \mathrm{mM} \mathrm{MgCl}, 10 \mathrm{mM} \mathrm{HEPES}$, $10 \mathrm{mM}$ glucose, pH 7.3, 320 mOsm. The whole-cell pipette solution contained $145 \mathrm{mM} \mathrm{CsCl}, 5 \mathrm{mM}$ EGTA, $3 \mathrm{mM} \mathrm{CaCl}$, $10 \mathrm{mM} \mathrm{HEPES}$, 2 mM MgATP, pH 7.3, 290 mOsm. Methods of transfection and recording were as described in (Hynkova et al. 2016).

Recently, a comprehensive pharmacological and transcriptomic studies performed on immortalized cell lines derived from dorsal root ganglion neurons demonstrated that F11 cells highly express bradykinin
$\mathrm{B}_{2}$ receptor and exhibit robust responses to subnanomolar concentrations of bradykinin (Vetter and Lewis 2010, Yin et al. 2016). These findings prompted us to explore whether the known proalgesic effects of bradykinin could 
involve a direct regulation of TRPA1 under ex vivo conditions. We used calcium imaging technique as described previously by us in (Marsakova et al. 2012) and measured responses from F11 cells. In our hands, bradykinin at a concentration of $10 \mathrm{nM}$ elicited large $\mathrm{Ca}^{2+}$ transients in all naïve F11 cells (Fig. 3A), similarly as previously described by Vetter and Lewis (2010). The amplitude of the second response to bradykinin applied $3 \mathrm{~min}$ later was substantially lower than the initial response. Next, we co-transfected F11 cells with cDNA encoding human TRPA1 together with green fluorescent protein (GFP) and measured intracellular $\mathrm{Ca}^{2+}$ responses to addition of $10 \mathrm{nM}$ bradykinin. As shown in
Figures 3B, C and D, TRPA1-expressing cells exhibited increased basal calcium levels likely due to constitutively opened TRPA1 channels (Karashima et al. 2008). The cells responded to bradykinin in a very similar manner as GFP-negative cells, indicating no sensitizing effects on TRPA1. Only occasionally, we observed spontaneous calcium transients in TRPA1-expressing cells. When bradykinin was applied to cells pre-activated by allyl-isothiocyanate (Fig. 3D), the $\mathrm{Ca}^{2+}$ responses were only transient and at least in part additive, indicating that, most likely, TRPA1 channels do not undergo long-term modulation caused by bradykinin-triggered phosphorylation.

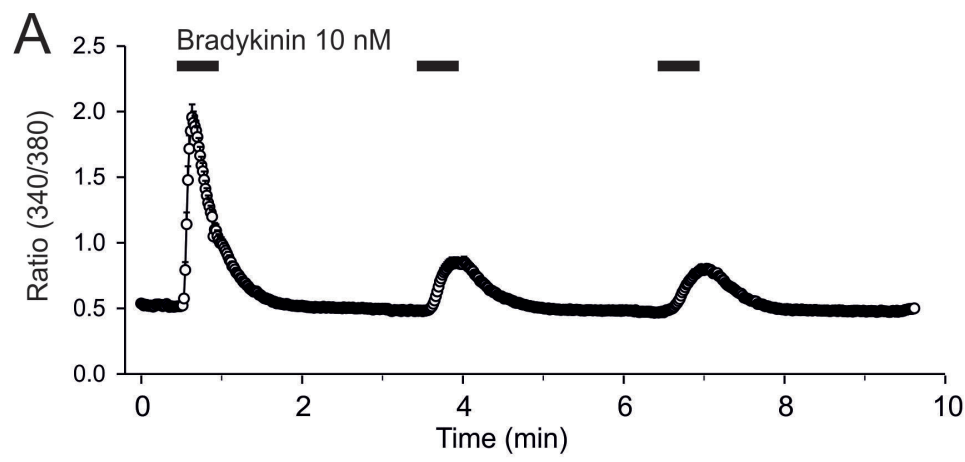

B
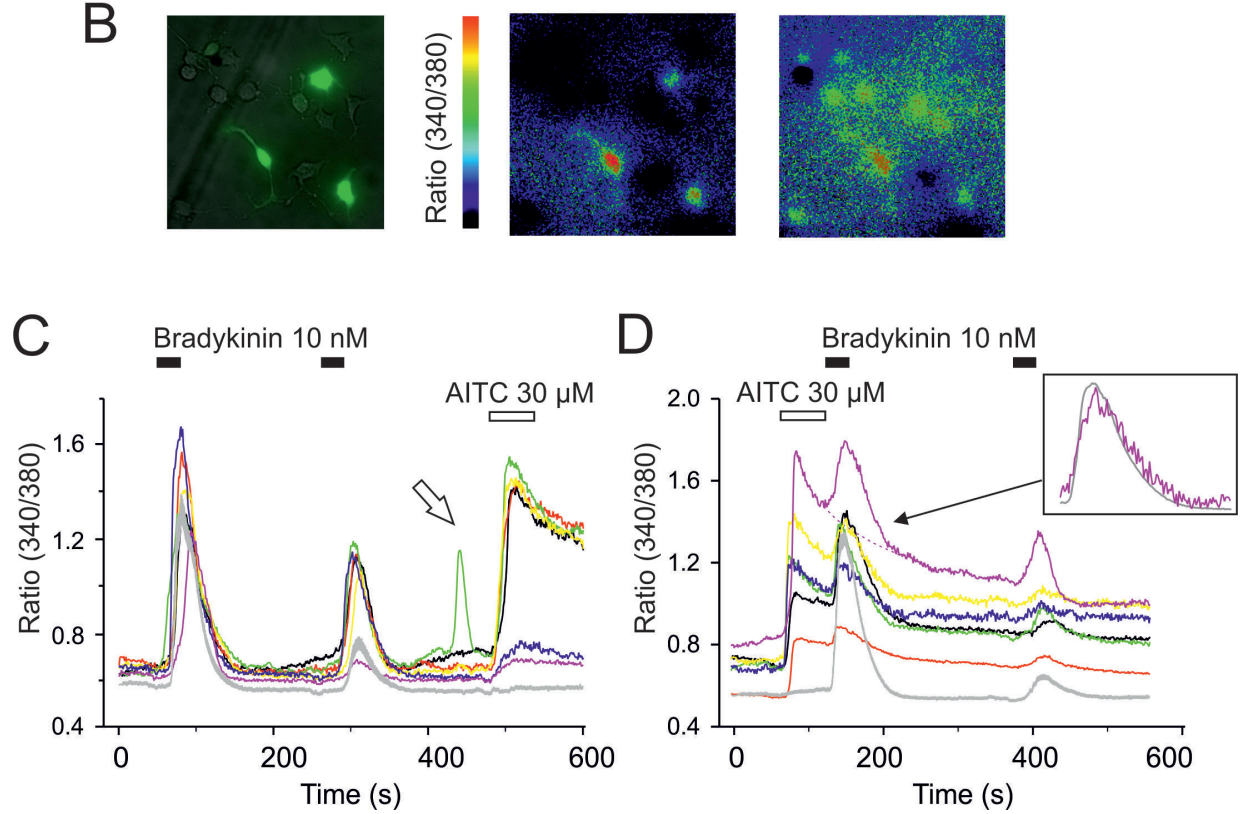

Fig. 3. Calcium imaging experiments in F11 cells. (A) Changes in the Fura-2 ratio measured in naïve F11 cells exposed to 3 subsequent applications of $10 \mathrm{nM}$ bradykinin. Data are represented as mean \pm SEM of $n=85$ cells and are representative of 5 independent experiments. (B) GFP-fluorescence marks the cells expressing TRPA1 (left). Pseudocolored images of the 340/380 nm Fura-2 ratio show cells captured at the peak of AITC-induced (middle) and at the peak of bradykinin-induced transients (right), as shown in D. (C) Bradykinin induced large calcium transients but did not affect TRPA1 channels. Representative traces for individual TRPA1-expressing cells are shown in color, the average calcium response of F11 cells unresponsive to allyl isothiocyanate (AITC, $30 \mu \mathrm{M}$ ) is shown as a gray line surrounded by the gray area representing SEM $(n=14)$. The white arrow denotes spontaneous calcium transient. (D) Expression of TRPA1 did not affect the magnitude or duration of the $\mathrm{Ca}^{2+}$ response to bradykinin compared to $\mathrm{F} 11$ control cells. The average calcium response for F11 cells unresponsive to AITC $(30 \mu \mathrm{M})$ is shown as a gray line surrounded by the gray area representing SEM $(n=19)$. The inset shows the averaged response from cells unresponsive to AITC (gray line) and the response obtained by digital subtraction of the AITC response interpolated by exponential fitting over the interval 120-210 s (purple dashed line) from the original AITC trace (purple solid line). It is apparent that normalized responses overlap in time. 


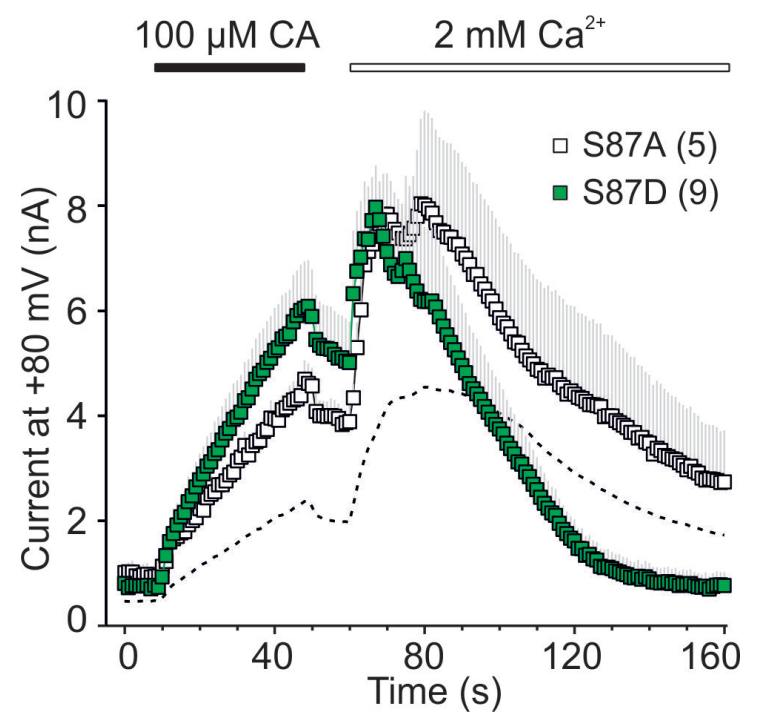

Fig. 4. Phospho-mimicking and phospho-null substitutions at serine S87. Time course of average whole-cell currents through the wild-type human TRPA1 (dashed line, $n=70$ ) and the S87A $(n=5)$ and S87D $(n=9)$ mutants measured at $+80 \mathrm{mV}$. The average currents are shown with gray bars indicating SEM. The number of cells is given in parentheses. Whole-cell membrane currents were measured first in the absence of extracellular $\mathrm{Ca}^{2+}$ and in the presence of the partial agonist cinnamaldehyde (CA, $100 \mu \mathrm{M}$ for $40 \mathrm{~s})$. CA was then washed out for $10 \mathrm{~s}$ and $\mathrm{Ca}^{2+}$ at a concentration of $2 \mathrm{mM}$ was added to the extracellular solution. The membrane potential was ramped up each second from $-80 \mathrm{mV}$ to $+80 \mathrm{mV}(1 \mathrm{~V} / \mathrm{s}$; data are shown only at $+80 \mathrm{mV}$ ). Intracellular $\mathrm{Ca}^{2+}$ was buffered to low levels with $5 \mathrm{mM}$ EGTA in the patch pipette to assess the effects of permeating calcium ions. The application of $100 \mu \mathrm{M}$ CA and subsequent addition of $2 \mathrm{mM} \mathrm{Ca}{ }^{2+}$ are indicated above. The experimental methods and solutions used for whole-cell recordings are described in detail in Hynkova et al. (2016).

Although further experiments are necessary to fully understand the mechanisms, the apparent conclusion from these illustrative examples is that the over-expression of TRPA1 may lead to an increase in cellular $\mathrm{Ca}^{2+}$, which ultimately activates the intracellular pathways enormously and makes their specific regulation more difficult. So what are the implications of these findings in relation to the potential phosphorylation targets on TRPA1 for kinases activated by inflammatory mediators? General and kinase-specific phosphorylation site predictions point to a number of serine and threonine residues within the primary sequence of human TRPA1 (Table 1). To decisively identify these sites would require an in-depth, systematic examination of a number of mutants in which individual serines, threonines or tyrosines are replaced either by a nonphosphorylatable residue (alanine or phenylalanine) or by an acidic residue mimicking phosphorylation (aspartate or glutamate). While this approach can provide information on putative role of the predicted sites, it also has several limitations that must be taken into account when interpreting the data. An example of an electrophysiological experiment, in which mutations at one of the predicted phosphorylation sites for PKA lead to a dramatic increase in TRPA1-mediated responses to cinnamaldehyde, is shown in Figure 4. Our unpublished electrophysiological results (Hynkova et al.) indicate that this increase in responsiveness was observed for both the alanine (open squares) and the aspartate (green squares) mutants. One may speculate that phosphorylation at serine S87 influences the functioning or targeting of TRPA1, however, a nonphosphorylatable residue at this position increased the responses as well. By considering that S87 is located at the beginning of the finger loop of predicted $\mathrm{N}$-terminal ankyrin repeat 1 , it is tempting to conclude that the effects we observe result from structural changes in this region. Another explanation, similarly plausible and not mutually exclusive, is that mutations at S87 influence immediately preceding serine S86 that is also predicted to be a phosphorylation site (Table 1).

\section{Cyclin-dependent kinase 5-mediated phos- phorylation of TRPA1}

Cyclin-dependent kinase 5 (Cdk5), a serine/threonine kinase, is predominantly expressed in neuronal tissues and plays an important role in inflammation-induced pain signaling (Pareek and Kulkarni 2006, Pareek et al. 2007, Utreras et al. 2009). It is involved in several cellular processes such as regulation of neuronal migration, axon guidance, synaptic structure and plasticity or membrane transport (Dhavan and Tsai 2001). Cdk5 belongs to a large group of cyclin-dependent kinases, however, it is neither activated by cyclins, nor does it participate in the cell cycle progression. Instead, association of $\mathrm{Cdk} 5$ with myristoylated p35 (or its splice variant p25) and/or p39 cofactors is required for activation of the kinase. As the p35 is a membrane-bound protein, physiological substrates of Cdk5 are likely to be transmembrane or membrane-associated proteins. Cdk5 is a prolinedirected kinase that phosphorylates serine or threonine residues immediately preceding a proline residue. Its consensus motif is $(\mathrm{S} / \mathrm{T}) \mathrm{PX}(\mathrm{K} / \mathrm{H} / \mathrm{R})$, where $\mathrm{S}$ and $\mathrm{T}$ are the phosphorylatable serine or threonine, $\mathrm{P}$ is a proline residue in the +1 position, and $\mathrm{X}$ is any amino acid (Songyang et al. 1996). 
Table 1. Predictions for putative phosphorylation sites in human TRPA1.

\begin{tabular}{|c|c|c|c|c|c|c|c|c|c|c|c|c|}
\hline \multirow[t]{2}{*}{$\mathbf{S} / \mathbf{T}$} & \multicolumn{3}{|c|}{ PKA } & \multicolumn{3}{|c|}{ PKC } & \multicolumn{3}{|c|}{ CDK5 } & \multicolumn{3}{|c|}{ Src } \\
\hline & NetPhos & $\begin{array}{c}\text { Scan- } \\
\text { Site }\end{array}$ & GPS & NetPhos & $\begin{array}{l}\text { Scan- } \\
\text { Site }\end{array}$ & GPS & NetPhos & $\begin{array}{c}\text { Scan- } \\
\text { Site }\end{array}$ & GPS & NetPhos & $\begin{array}{c}\text { Scan- } \\
\text { Site }\end{array}$ & GPS \\
\hline$S 4$ & - & - & - & 0.8 & - & 13 & - & - & - & - & - & - \\
\hline$Y 22$ & - & - & - & - & - & - & - & - & - & 0.542 & 0.553 & 9.8 \\
\hline S35 & - & 0.724 & - & 0.612 & 0.447 & 11.034 & - & - & - & - & - & - \\
\hline S86 & 0.773 & 0.711 & 3.893 & - & - & - & - & - & - & - & - & - \\
\hline$S 87$ & 0.559 & 0.562 & 3.714 & - & 0.493 & 5.455 & - & - & - & - & - & - \\
\hline$Y 97$ & - & - & - & - & - & - & - & - & - & 0.481 & - & 5.75 \\
\hline$T 100$ & - & - & - & - & - & - & 0.424 & 0.571 & 14.6 & - & - & - \\
\hline$T 241$ & - & - & 5.333 & - & - & - & 0.376 & 0.578 & 13.7 & - & - & - \\
\hline$T 274$ & 0.517 & 0.676 & 4.018 & - & - & - & - & - & - & - & - & - \\
\hline$S 317$ & 0.781 & 0.458 & 4.429 & - & - & - & - & - & - & - & - & - \\
\hline$S 344$ & - & - & - & - & - & - & 0.535 & 0.672 & 11.6 & - & - & - \\
\hline$T 415$ & - & - & - & - & - & - & 0.405 & 0.571 & 22.3 & - & - & - \\
\hline$S 438$ & - & - & - & - & 0.472 & 4.059 & - & - & - & - & - & - \\
\hline$S 443$ & - & - & - & 0.793 & - & 7.424 & - & - & - & - & - & - \\
\hline$S 448$ & - & 0.673 & 6.333 & - & - & - & 0.465 & 0.433 & 18.2 & - & - & - \\
\hline$T 484$ & - & - & - & - & - & - & 0.518 & 0.543 & 20.1 & - & - & - \\
\hline T598 & - & - & - & 0.824 & 0.537 & - & - & - & - & - & - & - \\
\hline S616 & - & - & - & - & - & - & 0.471 & 0.546 & 9.3 & - & - & - \\
\hline T673 & - & 0.617 & 4.667 & - & - & - & 0.478 & 0.616 & 11 & - & - & - \\
\hline Y680 & - & - & - & - & - & - & - & - & - & 0.461 & 0.533 & 12.813 \\
\hline$S 972$ & 0.27 & 0.657 & 4.043 & 0.71 & 0.498 & 9.96 & - & - & - & - & - & - \\
\hline S1012 & 0.627 & 0.72 & - & - & - & - & - & - & - & - & - & - \\
\hline$T 1055$ & - & 0.623 & 1.037 & - & - & - & - & - & - & - & - & - \\
\hline S1101 & 0.751 & 0.737 & 4.607 & - & - & - & - & - & - & - & - & - \\
\hline T1105 & 0.234 & 0.599 & - & 0.672 & - & 10.813 & - & - & - & - & - & - \\
\hline$T 1114$ & - & - & - & 0.537 & - & 11.672 & - & - & - & - & - & - \\
\hline
\end{tabular}

Comparisons of the score values for the predicted residues obtained from three prediction servers NetPhosK2.0: http://www.cbs.dtu.dk/services/NetPhos/, ScanSite3: http://scansite3.mit.edu/, and GPS: http://gps.biocuckoo.org/. Phosphorylation sites predicted unanimously are highlighted by yellow.

The co-expression of TRPA1 with the p35 alone or with Cdk5 and p35 in HEK 293T cells significantly increased the cinnamaldehyde-evoked responses of human TRPA1 (Hynkova et al. 2016), indicating that TRPA1 may be a substrate for the Cdk5/p35 complex and/or its interaction with p35 may stabilize the activated state of the channel (Fig. 5A). As candidate residues for phosphorylation by Cdk5 in TRPA1, the N-terminal threonines T100, T241, T415, T484 and serine S448, which are located in highly conserved T/SPLH ankyrin motifs, were predicted in our recent study (Hynkova et al. 2016) at a high stringency level (Table 1). The N-terminal part of TRPA1, constituting more than a half of the protein size, encompasses a tandem array of 17 ankyrin repeats (AR1-AR17) that have been described as an integrator of various activation stimuli: electrophilic agents, cold or calcium ions (Hinman et al. 2006, Macpherson et al. 2007, Zurborg et al. 2007, Jabba et al. 2014). The ankyrin repeat is a common structural motif, typically of 33 amino acid residues, which forms an anti-parallel helix-turn-helix structure followed by a $\beta$-hairpin loop. Five of seventeen ARs of human TRPA1 contain a tetrapeptide motif T/SPLH, which is highly conserved among ankyrin proteins. In such a motif, proline initiates the first $\alpha$-helix, whereas the pair of threonine and histidine forms intra- and inter-repeat 
bonds thus contributing to local conformational stability of the AR (Li et al. 2006, Gaudet 2008, Guo et al. 2010). The neighboring ankyrin repeats tend to stack together and form elongated domains, which are important for protein-protein interactions (Corey et al. 2004, Sotomayor et al. 2005) and can serve as the binding sites for non-protein ligands such as adenosine triphosphate (Lishko et al. 2007).

Based on the consensus sequence, the $\mathrm{N}$-terminal tetrapeptide T/SPLH motifs in TRPA1 can serve as putative phosphorylation sites TRPA1 for proline-targeted Ser/Thr kinases such as Cdk5. On the other hand, even subtle structural changes introduced by mutations at ankyrin repeat consensus residues can profoundly impact the structure or result in an unstable protein (Gaudet 2008). Indeed, recently the site-directed mutagenesis and patch clamp experiments suggested that the examined serine and threonine residues within these T/SPLH motifs are not likely to be involved in phosphorylation because the phosphonull alanine mutations and phosphorylation mimicking aspartate mutations did not lead to opposite changes in the channel functioning. It has been previously shown that a 58 -AA peptide (C421-D479) containing S448 was phosphorylated by Cdk5 in vitro (Sulak 2011). However, the phospho-mimicking aspartate mutation of this serine residue in the TRPA1 channel resulted in a non-functional phenotype (Hynkova et al. 2016).

Further sequence prediction analysis of the TRPA1 N-terminus revealed additional three putative phosphorylation sites for Cdk5: serine and threonine residues S344, S616, and T673. Among these, only the T673D mutation resulted in channels whose responses to the agonist cinnamaldehyde were increased almost threefold compared with wild-type (Fig. 5B). According to the TRPA1 structure, threonine T673 is solventaccessible and located in a flexible loop connecting the $\beta$-strands to the helix-turn-helix motif preceding the pre-S1 helix, indicating that it may represent a candidate target for Ser/Thr phosphorylation.

In sensory neurons expressing TRPV1, increased activity of Cdk5 is associated with elevated levels of phosphorylated threonine T407 at TRPV1, increased surface distribution and TRPV1-mediated $\mathrm{Ca}^{2+}$ influx (Liu et al. 2015, Rozas et al. 2016). Although two threonine and one serine residues in the primary sequence of TRPV1 correspond to the consensus, only the threonine T407 is a target residue for Cdk5 (Pareek et al. 2007). The co-expression of Cdk5 and p35 with TRPV1
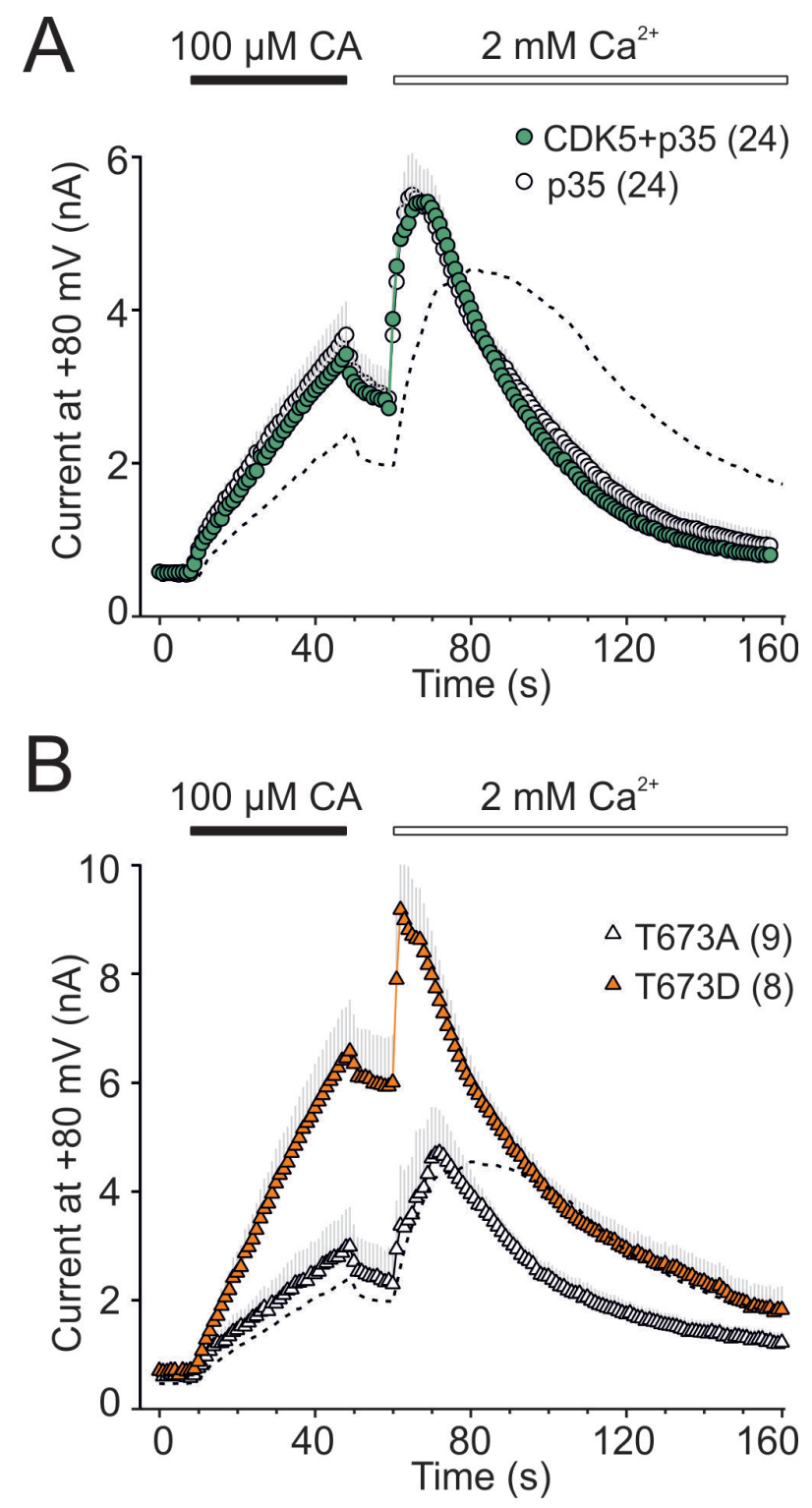

Fig. 5. Threonine $T 673$ as a putative phosphorylation site for Cdk5. (A) Co-expression of TRPA1 with Cdk5 kinase and p35, a Cdk5-specific activator, significantly increased TRPA1-mediated responses to cinnamaldehyde (CA), indicating that TRPA1 may be a substrate for the CDK5/p35 complex and/or its interaction with p35 may stabilize the activated state. Whole-cell recordings were obtained using the same protocol as in Figure 4. The number of cells is given in parentheses. (B) The T673D mutation resulted in channels whose responses to cinnamaldehyde were increased almost threefold, whereas the mutant T673A channels remained largely unchanged. Threonine T673 is solvent-accessible and located in a flexible loop connecting the $\beta$-strands to the helix-turn-helix motif preceding the pre-S1 helix, i.e. well situated in a locus especially important for the detection, integration and transmission of activation stimuli (Paulsen et al. 2015). Thus, T673 may represent a candidate target for Ser/Thr phosphorylation by Cdk5 (adapted Fig. 7, panel C, and Fig. 8, panel B from Hynkova et al. 2016).

as well as the mutation of threonine T407 to aspartate had the same effect on the function of the channel - both reduced the TRPV1 $\mathrm{Ca}^{2+}$-dependent desensitization 
(Jendryke et al. 2016). TRPV1 and TRPA1 are expressed in partially overlapping subsets of nociceptive neurons and thus it is likely that both ion channels act in tandem as the important targets for $\mathrm{Cdk} 5$.

\section{C-terminus of TRPA1 as a putative target for protein kinase CK2?}

Protein kinase CK2, formerly known as casein kinase II, is a ubiquitous and highly conserved protein serine/threonine kinase whose activity is independent of cyclic nucleotides and calcium. It has been linked to a number of human disorders, including neurodegenerative diseases and inflammatory response (Singh and Ramji 2008, Perez et al. 2011). CK2 is an acidophilic kinase, requiring an acidic residue (either aspartate or glutamate) three residues from the C-terminal of the phosphate acceptor site. In the consensus motif $\mathrm{S} / \mathrm{T}-\mathrm{X}-\mathrm{X}-$ $\mathrm{D} / \mathrm{E}$, serine is favored over threonine; $\mathrm{X}$ can be any nonbasic amino acid. Additional acidic residues in positions $+1,+2,+4$, and +5 increase the phosphorylation rate and aspartate is preferred to glutamate (St-Denis et al. 2015). Within the C-terminal region of human TRPA1, there are two strong consensus phosphorylation motifs containing the serine S1076 and the threonine T1078 $\left({ }^{1071}\right.$ KMEIISETEDD $^{1081}$ and ${ }^{1073}$ EIISETEDDDS $\left.{ }^{1083}\right)$, both predicted to be targeted by casein kinase CK2 (NetPhorest Posterior probability of 0.6386 and 0.6261 ; (Sura et al. 2012). A similar acidic cluster has been reported to constitute a cytosolic sorting motif that, upon CK2 phosphorylation, controls the trafficking and surface expression of TRPA1-related TRPP2 and TRPV4 channels (Kottgen et al. 2005). In our recent study by Sura et al. (2012), we compared four constructs of human TRPA1 in which either serine or threonine were replaced by either alanine or aspartate to mimic the non-phosphorylated and phosphorylated forms of the protein, respectively. In this study, we showed that the aspartate mutation T1078D exhibited the gain of function phenotype. The alanine mutations S1076A and T1078A and the phosphorylation mimicking mutation S1076D resembled the wild-type phenotype which indicates that the functional changes caused by substitutions in this region are not likely to be caused by disturbed phosphorylation. Instead, we demonstrated that the highly conserved sequence ${ }^{1077}$ ETEDDD $^{1082}$ may act as a binding site for calcium ions, similar as the $\mathrm{Ca}^{2+}$-binding domain found in the $\mathrm{Ca}^{2+}$-binding domain of the superfamily of BK channels (Sura et al. 2012).

\section{Regulation of TRPA1 by Src tyrosine kinase}

Nerve growth factor (NGF) regulates chronic inflammatory hyperalgesia by controlling gene expression in sensory neurons. NGF, acting on the receptor TrkA, initiates a signaling pathway in which phosphoinositide 3-kinase plays an essential early role. A downstream element of this signaling cascade is the tyrosine-protein Src kinase which binds to and phosphorylates proteins at tyrosine residues. One of the Src-kinase targets is TRPV1 in which phosphorylation at a single residue Y200 promotes trafficking of the receptor to the surface membrane (Zhang et al. 2005). In the presence of NGF, TRPA1 expression is also up-regulated (Obata et al. 2005, Diogenes et al. 2007); however, a direct evidence of Src kinase mediated phosphorylation of TRPA1 is still lacking. The apparent candidates are tyrosines Y22, Y97 and Y680, predicted with high stringency by a number of prediction servers (Table 1). Recently, TRPA1 has been shown to be regulated by a Src family tyrosine kinase inhibitor PP2 in the SH-SY5Y cell line (Morgan et al. 2014). The cells expressing TRPA1 gradually lost detectable response to agonist when cultured for more than $10-15$ passages but the responses could be retrieved rapidly by short pre-treatment with PP2. The authors individually mutated several tyrosine residues with the aim to identify the putative tyrosine residues responsible for this effect (Y69C, Y97F, Y226F, and Y654F/Y655F). Of these, only Y69C was not affected by pre-treatment with PP2. Interestingly, the authors could not repeat this experiment in HEK293 cells because the PP2 inhibitor elicited large elevations in intracellular $\mathrm{Ca}^{2+}$.

\section{N-linked glycosylation of TRPA1}

Among other TRP channels, TRPA1 has a distinctive structural feature: its outer pore domain contains two pore helices instead of the typical solitary one present in TRPV1, TRPV2, TRPV6 and in the TRP-related family of voltage-gated potassium $\left(\mathrm{K}_{\mathrm{V}}\right)$ channels (Paulsen et al. 2015). Another apparent difference, related to the presumptive gating mechanism, resides in the existence of a short linker connecting $\mathrm{S} 1$ and S2. In TRPV1, the S1-S2 linker lies atop the S1-S4 bundle and is static (Cao et al. 2013). In TRPA1, this region extends into the extracellular space. A poorly resolved density map in this region suggests that the S1-S2 linker possesses intrinsic structural flexibility, and 
thus may be actively involved in channel gating. Within this region, two putative glycosylation sites $\left({ }^{747} \mathrm{NSTG}\right.$ and ${ }^{753}$ NETS) have been predicted (Jaquemar et al. 1999). Independent mutagenesis studies confirmed the structural importance of both asparagine residues. Despite the glycosylation of TRPA1 has not been identified in native cells yet, a population of "mature" FLAG-tagged human TRPA1 receptor expressed in HEK293 cells was recently described (Egan et al. 2016). These authors show that both of these predicted sites can be modified with an N-glycan and that the glycan at position N747 modulates agonist-sensitivity of TRPA1 in vitro. The authors showed that the agonist sensitivity of TRPA1 was significantly decreased in mutants N747Q and N747Q-N753Q but not in N753Q and the expression level of the double mutant was significantly lower. Moreover, the N747Q mutation influenced the efficiency of glycoprocessing of the N-glycan bound at N753. Another study showed that alanine mutations of these two asparagines are comparably sensitive to electrophiles AITC and 3,5-di-tert-butylphenol. The N753A mutant was much less sensitive to coal fly ash, the prototype particulate matter pollutant, indicating that this residue is involved in mechanical activation of TRPA1 (Deering-Rice et al. 2015).

In our laboratory, using GFP-tagged TRPA1 in HEK 293T cells, we failed to observe any glycosylation (Marsakova et al. 2017). The sensitivity to agonist was not different from control measurements in cells that were treated with tunicamycin that prevents $\mathrm{N}$-glycosylation of proteins. The AITC responses through the N747T-N753T double mutant were much less rectified at negative membrane potentials whereas immunoblot analysis showed that this double mutant achieved in average only about $80 \%$ of the total wild-type TRPA1 surface expression. The functional changes were thus attributed to structural changes in the S1-S2 loop that is crucial for proper expression.

\section{Concluding remarks}

Better knowledge of the structural mechanisms underlying phosphorylation and other post-translational modifications is an important prerequisite if one wishes to understand how the signaling pathways may contribute to changes in nociception during normal and pathological states. It has been recognized that the study of these processes is very challenging due to tissue specificity, thus the experiments in heterologous expression systems must be interpreted with caution. Nevertheless, there is a progress in the identification of various signaling pathways involved in the sensitization of the TRP channels by pro-inflammatory agents. At the same time, the unknown identity of specific sites underlying these processes signifies a gap in our understanding of how these channels are capable of transducing and modulating pain.

\section{Author Note}

During the review process, a study was published identifying four amino acid residues (S86, S317, S428, and S972) as the principal targets of PKA-mediated phosphorylation and sensitization of human TRPA1 (Meents et al. 2017). The findings confirm our predictions and may partly explain our data presented in Figure 4 of this review.

\section{Conflict of Interest}

There is no conflict of interest.

\section{Acknowledgements}

This work was supported by the Czech Science Foundation (15-15839S), the Grant Agency of Charles University (GA UK 888513 and 365215) and by the Ministry of Health of the Czech Republic (NV16-28784A).

\section{References}

ANDRADE EL, MEOTTI FC, CALIXTO JB: TRPA1 antagonists as potential analgesic drugs. Pharmacol Ther 133: 189-204, 2012.

BAHIA PK, PARKS TA, STANFORD KR, MITCHELL DA, VARMA S, STEVENS SM, JR, TAYLOR-CLARK TE: The exceptionally high reactivity of Cys 621 is critical for electrophilic activation of the sensory nerve ion channel TRPA1. J Gen Physiol 147: 451-465, 2016.

BANDELL M, STORY GM, HWANG SW, VISWANATH V, EID SR, PETRUS MJ, EARLEY TJ, PATAPOUTIAN A: Noxious cold ion channel TRPA1 is activated by pungent compounds and bradykinin. Neuron 41: 849-857, 2004. 
BAUTISTA DM, JORDT SE, NIKAI T, TSURUDA PR, READ AJ, POBLETE J, YAMOAH EN, BASBAUM AI, JULIUS D: TRPA1 mediates the inflammatory actions of environmental irritants and proalgesic agents. Cell 124: 1269-1282, 2006.

BAUTISTA DM, PELLEGRINO M, TSUNOZAKI M: TRPA1: A gatekeeper for inflammation. Annu Rev Physiol 75: 181-200, 2013.

BREWSTER MS, GAUDET R: How the TRPA1 receptor transmits painful stimuli: Inner workings revealed by electron cryomicroscopy. Bioessays 37: 1184-1192, 2015.

CAO E, LIAO M, CHENG Y, JULIUS D: TRPV1 structures in distinct conformations reveal activation mechanisms. Nature 504: 113-118, 2013.

CAVANAUGH EJ, SIMKIN D, KIM D: Activation of transient receptor potential A1 channels by mustard oil, tetrahydrocannabinol and $\mathrm{Ca}(2+)$ reveals different functional channel states. Neuroscience 154: 1467-1476, 2008.

CHEN J, HACKOS DH: TRPA1 as a drug target--promise and challenges. Naunyn Schmiedebergs Arch Pharmacol 388: 451-463, 2015.

CHEN JJ, JOHNSON EJ: Targeting the bradykinin B1 receptor to reduce pain. Expert Opin Ther Targets 11: 21-35, 2007.

COREY DP, GARCIA-ANOVEROS J, HOLT JR, KWAN KY, LIN SY, VOLLRATH MA, AMALFITANO A, CHEUNG EL, DERFLER BH, DUGGAN A, ET AL:: TRPA1 is a candidate for the mechanosensitive transduction channel of vertebrate hair cells. Nature 432: 723-730, 2004.

CVETKOV TL, HUYNH KW, COHEN MR, MOISEENKOVA-BELL VY: Molecular architecture and subunit organization of TRPA1 ion channel revealed by electron microscopy. J Biol Chem 286: 38168-38176, 2011.

DAI Y, WANG S, TOMINAGA M, YAMAMOTO S, FUKUOKA T, HIGASHI T, KOBAYASHI K, OBATA K, YAMANAKA $\mathrm{H}$, NOGUCHI K: Sensitization of TRPA1 by PAR2 contributes to the sensation of inflammatory pain. J Clin Invest 117: 1979-1987, 2007.

DEERING-RICE CE, SHAPIRO D, ROMERO EG, STOCKMANN C, BEVANS TS, PHAN QM, STONE BL, FASSL B, NKOY F, UCHIDA DA, ET AL.: Activation of transient receptor potential ankyrin-1 by insoluble particulate material and association with asthma. Am J Respir Cell Mol Biol 53: 893-901, 2015.

DHAVAN R, TSAI LH: A decade of CDK5. Nat Rev Mol Cell Biol 2: 749-759, 2001.

DIOGENES A, AKOPIAN AN, HARGREAVES KM: NGF up-regulates TRPA1: implications for orofacial pain. $J$ Dent Res 86: 550-555, 2007.

DOERNER JF, GISSELMANN G, HATT H, WETZEL CH: Transient receptor potential channel A1 is directly gated by calcium ions. J Biol Chem 282: 13180-13189, 2007.

EGAN TJ, ACUÑA MA, ZENOBI-WONG M, ZEILHOFER HU, URECH D: Effects of N-Glycosylation of the human cation channel TRPA1 on agonist-sensitivity. Biosci Rep 36: e00390, 2016.

FRANCEL PC, HARRIS K, SMITH M, FISHMAN MC, DAWSON G, MILLER RJ: Neurochemical characteristics of a novel dorsal root ganglion X neuroblastoma hybrid cell line, F-11. J Neurochem 48: 1624-1631, 1987.

GAO Y, CAO E, JULIUS D, CHENG Y: TRPV1 structures in nanodiscs reveal mechanisms of ligand and lipid action. Nature 534: 347-351, 2016.

GAUDET R: A primer on ankyrin repeat function in TRP channels and beyond. Mol Biosyst 4: 372-379, 2008.

GEPPETTI P, NASSINI R, MATERAZZI S, BENEMEI S: The concept of neurogenic inflammation. BJU Int 101 (Suppl 3): 2-6, 2008.

GUO Y, YUAN C, TIAN F, HUANG K, WEGHORST CM, TSAI MD, LI J: Contributions of conserved TPLH tetrapeptides to the conformational stability of ankyrin repeat proteins. J Mol Biol 399: 168-181, 2010.

GUSTAVSSON N, WU B, HAN W: Calcium sensing in exocytosis. Adv Exp Med Biol 740: 731-757, 2012.

HINMAN A, CHUANG HH, BAUTISTA DM, JULIUS D: TRP channel activation by reversible covalent modification. Proc Natl Acad Sci U S A 103: 19564-19568, 2006.

HUYNH KW, COHEN MR, JIANG J, SAMANTA A, LODOWSKI DT, ZHOU ZH, MOISEENKOVA-BELL VY: Structure of the full-length TRPV2 channel by cryo-EM. Nat Commun 7: 11130, 2016.

HYNKOVA A, MARSAKOVA L, VASKOVA J, VLACHOVA V: N-terminal tetrapeptide T/SPLH motifs contribute to multimodal activation of human TRPA1 channel. Sci Rep 6: 28700, 2016. 
JABBA S, GOYAL R, SOSA-PAGAN JO, MOLDENHAUER H, WU J, KALMETA B, BANDELL M, LATORRE R, PATAPOUTIAN A, GRANDL J: Directionality of temperature activation in mouse TRPA1 ion channel can be inverted by single-point mutations in ankyrin repeat six. Neuron 82: 1017-1031, 2014.

JAQUEMAR D, SCHENKER T, TRUEB B: An ankyrin-like protein with transmembrane domains is specifically lost after oncogenic transformation of human fibroblasts. J Biol Chem 274: 7325-7333, 1999.

JENDRYKE T, PROCHAZKOVA M, HALL BE, NORDMANN GC, SCHLADT M, MILENKOVIC VM, KULKARNI AB, WETZEL CH: TRPV1 function is modulated by Cdk5-mediated phosphorylation: insights into the molecular mechanism of nociception. Sci Rep 6: 22007, 2016.

JORDT SE, BAUTISTA DM, CHUANG HH, MCKEMY DD, ZYGMUNT PM, HOGESTATT ED, MENG ID, JULIUS D: Mustard oils and cannabinoids excite sensory nerve fibres through the TRP channel ANKTM1. Nature 427: 260-265, 2004.

KARASHIMA Y, PRENEN J, MESEGUER V, OWSIANIK G, VOETS T, NILIUS B: Modulation of the transient receptor potential channel TRPA1 by phosphatidylinositol 4,5-biphosphate manipulators. Pflugers Arch 457: 77-89, 2008.

KARASHIMA Y, PRENEN J, TALAVERA K, JANSSENS A, VOETS T, NILIUS B: Agonist-induced changes in $\mathrm{Ca}(2+)$ permeation through the nociceptor cation channel TRPA1. Biophys $J$ 98: 773-783, 2010.

KOTTGEN M, BENZING T, SIMMEN T, TAUBER R, BUCHHOLZ B, FELICIANGELI S, HUBER TB, SCHERMER B, KRAMER-ZUCKER A, HOPKER K, ET AL.: Trafficking of TRPP2 by PACS proteins represents a novel mechanism of ion channel regulation. EMBO J 24: 705-716, 2005.

KWAN KY, ALLCHORNE AJ, VOLLRATH MA, CHRISTENSEN AP, ZHANG DS, WOOLF CJ, COREY DP: TRPA1 contributes to cold, mechanical, and chemical nociception but is not essential for hair-cell transduction. Neuron 50: 277-289, 2006.

LAURSEN WJ, BAGRIANTSEV SN, GRACHEVA EO: TRPA1 channels: chemical and temperature sensitivity. Curr Top Membr 74: 89-112, 2014.

LI J, MAHAJAN A, TSAI MD: Ankyrin repeat: a unique motif mediating protein-protein interactions. Biochemistry 45 : 15168-15178, 2006.

LIAO M, CAO E, JULIUS D, CHENG Y: Structure of the TRPV1 ion channel determined by electron cryo-microscopy. Nature 504: 107-112, 2013.

LISHKO PV, PROCKO E, JIN X, PHELPS CB, GAUDET R: The ankyrin repeats of TRPV1 bind multiple ligands and modulate channel sensitivity. Neuron 54: 905-918, 2007.

LIU J, DU J, YANG Y, WANG Y: Phosphorylation of TRPV1 by cyclin-dependent kinase 5 promotes TRPV1 surface localization, leading to inflammatory thermal hyperalgesia. Exp Neurol 273: 253-262, 2015.

MACPHERSON LJ, DUBIN AE, EVANS MJ, MARR F, SCHULTZ PG, CRAVATT BF, PATAPOUTIAN A: Noxious compounds activate TRPA1 ion channels through covalent modification of cysteines. Nature 445: 541-545, 2007.

MARSAKOVA L, BARVIK I, ZIMA V, ZIMOVA L, VLACHOVA V: The first extracellular linker is important for several aspects of the gating mechanism of human TRPA1 channel. Front Mol Neurosci 10: 16, 2017.

MARSAKOVA L, TOUSKA F, KRUSEK J, VLACHOVA V: Pore helix domain is critical to camphor sensitivity of transient receptor potential vanilloid 1 channel. Anesthesiology 116: 903-917, 2012.

MEENTS JE, FISCHER MJ, MCNAUGHTON PA: Agonist-induced sensitisation of the irritant receptor ion channel TRPA1. J Physiol 594: 6643-6660, 2016.

MEENTS JE, FISCHER MJ, MCNAUGHTON PA: Sensitization of TRPA1 by protein kinase A. PloS One 12: e0170097, 2017.

MIYAMOTO T, DUBIN AE, PETRUS MJ, PATAPOUTIAN A: TRPV1 and TRPA1 mediate peripheral nitric oxide-induced nociception in mice. PLoS One 4: e7596, 2009.

MIZUMURA K, SUGIURA T, KATANOSAKA K, BANIK RK, KOZAKI Y: Excitation and sensitization of nociceptors by bradykinin: what do we know? Exp Brain Res 196: 53-65, 2009.

MORGAN K, SADOFSKY LR, CROW C, MORICE AH: Human TRPM8 and TRPA1 pain channels, including a gene variant with increased sensitivity to agonists (TRPA1 R797T), exhibit differential regulation by SRC-tyrosine kinase inhibitor. Biosci Rep 34: e00131, 2014. 
NAGATA K, DUGGAN A, KUMAR G, GARCIA-ANOVEROS J: Nociceptor and hair cell transducer properties of TRPA1, a channel for pain and hearing. J Neurosci 25: 4052-4061, 2005.

NILIUS B, APPENDINO G, OWSIANIK G: The transient receptor potential channel TRPA1: from gene to pathophysiology. Pflugers Arch 464: 425-458, 2012.

NILIUS B, PRENEN J, OWSIANIK G: Irritating channels: the case of TRPA1. J Physiol 589: 1543-1549, 2011.

OBATA K, KATSURA H, MIZUSHIMA T, YAMANAKA H, KOBAYASHI K, DAI Y, FUKUOKA T, TOKUNAGA A, TOMINAGA M, NOGUCHI K: TRPA1 induced in sensory neurons contributes to cold hyperalgesia after inflammation and nerve injury. J Clin Invest 115: 2393-2401, 2005.

OWSIANIK G, TALAVERA K, VOETS T, NILIUS B: Permeation and selectivity of TRP channels. Annu Rev Physiol 68: $685-717,2006$.

PALOVCAK E, DELEMOTTE L, KLEIN ML, CARNEVALE V: Comparative sequence analysis suggests a conserved gating mechanism for TRP channels. J Gen Physiol 146: 37-50, 2015.

PAREEK TK, KELLER J, KESAVAPANY S, AGARWAL N, KUNER R, PANT HC, IADAROLA MJ, BRADY RO, KULKARNI AB: Cyclin-dependent kinase 5 modulates nociceptive signaling through direct phosphorylation of transient receptor potential vanilloid 1. Proc Natl Acad Sci U S A 104: 660-665, 2007.

PAREEK TK, KULKARNI AB: Cdk5: a new player in pain signaling. Cell Cycle 5: 585-588, 2006.

PAULSEN CE, ARMACHE JP, GAO Y, CHENG Y, JULIUS D: Structure of the TRPA1 ion channel suggests regulatory mechanisms. Nature 520: 511-517, 2015.

PEREZ DI, GIL C, MARTINEZ A: Protein kinases CK1 and CK2 as new targets for neurodegenerative diseases. Med Res Rev 31: 924-954, 2011.

PETHO G, REEH PW: Sensory and signaling mechanisms of bradykinin, eicosanoids, platelet-activating factor, and nitric oxide in peripheral nociceptors. Physiol Rev 92: 1699-1775, 2012.

ROHACS T: Phosphoinositide regulation of non-canonical transient receptor potential channels. Cell Calcium 45 : 554-565, 2009.

ROZAS P, LAZCANO P, PINA R, CHO A, TERSE A, PERTUSA M, MADRID R, GONZALEZ-BILLAULT C, KULKARNI AB, UTRERAS E: Targeted overexpression of tumor necrosis factor-alpha increases cyclindependent kinase 5 activity and TRPV1-dependent Ca2+ influx in trigeminal neurons. Pain 157: 1346-1362, 2016.

SAOTOME K, SINGH AK, YELSHANSKAYA MV, SOBOLEVSKY AI: Crystal structure of the epithelial calcium channel TRPV6. Nature 534: 506-511, 2016.

SCHMIDT M, DUBIN AE, PETRUS MJ, EARLEY TJ, PATAPOUTIAN A: Nociceptive signals induce trafficking of TRPA1 to the plasma membrane. Neuron 64: 498-509, 2009.

SINGH NN, RAMJI DP: Protein kinase CK2, an important regulator of the inflammatory response? J Mol Med 86: 887-897, 2008.

SONGYANG Z, LU KP, KWON YT, TSAI LH, FILHOL O, COCHET C, BRICKEY DA, SODERLING TR, BARTLESON C, GRAVES DJ, DEMAGGIO AJ, HOEKSTRA MF, BLENIS J, HUNTER T, CANTLEY LC: A structural basis for substrate specificities of protein Ser/Thr kinases: primary sequence preference of casein kinases I and II, NIMA, phosphorylase kinase, calmodulin-dependent kinase II, CDK5, and Erk1. Mol Cell Biol 16: 6486-6493, 1996.

SOTOMAYOR M, COREY DP, SCHULTEN K: In search of the hair-cell gating spring elastic properties of ankyrin and cadherin repeats. Structure 13: 669-682, 2005.

ST-DENIS N, GABRIEL M, TUROWEC JP, GLOOR GB, LI SS, GINGRAS AC, LITCHFIELD DW: Systematic investigation of hierarchical phosphorylation by protein kinase CK2. J Proteomics 118: 49-62, 2015.

STARUSCHENKO A, JESKE NA, AKOPIAN AN: Contribution of TRPV1-TRPA1 interaction to the single channel properties of the TRPA1 channel. J Biol Chem 285: 15167-15177, 2010.

STORY GM, PEIER AM, REEVE AJ, EID SR, MOSBACHER J, HRICIK TR, EARLEY TJ, HERGARDEN AC, ANDERSSON DA, HWANG SW, MCINTYRE P, JEGLA T, BEVAN S, PATAPOUTIAN A: ANKTM1, a TRP-like channel expressed in nociceptive neurons, is activated by cold temperatures. Cell 112: 819-829, 2003. 
SULAK MA: Modulation of transient receptor potential cation channel, subfamily A, member 1 (TRPA1) activity by CDK5. In: Kent State University PhD Thesis, 2011, 84 p.

SURA L, ZIMA V, MARSAKOVA L, HYNKOVA A, BARVIK I, VLACHOVA V: C-terminal acidic cluster is involved in Ca2+-induced regulation of human transient receptor potential ankyrin 1 channel. J Biol Chem 287: 18067-18077, 2012.

TAKAHASHI N, KUWAKI T, KIYONAKA S, NUMATA T, KOZAI D, MIZUNO Y, YAMAMOTO S, NAITO S, KNEVELS E, CARMELIET P, OGA T, KANEKO S, SUGA S, NOKAMI T, YOSHIDA J, MORI Y: TRPA1 underlies a sensing mechanism for O2. Nat Chem Biol 7: 701-711, 2011.

TAYLOR-CLARK TE, UNDEM BJ, MACGLASHAN DW JR, GHATTA S, CARR MJ, MCALEXANDER MA: Prostaglandin-induced activation of nociceptive neurons via direct interaction with transient receptor potential A1 (TRPA1). Mol Pharmacol 73: 274-281, 2008.

UTRERAS E, FUTATSUGI A, PAREEK TK, KULKARNI AB: Molecular roles of Cdk5 in pain signaling. Drug Discov Today Ther Strateg 6: 105-111, 2009.

VETTER I, LEWIS RJ: Characterization of endogenous calcium responses in neuronal cell lines. Biochem Pharmacol 79: 908-920, 2010.

VIANA F: TRPA1 channels: molecular sentinels of cellular stress and tissue damage. $J$ Physiol 594: 4151-4169, 2016.

VOOLSTRA O, HUBER A: Post-translational modifications of TRP channels. Cells 3: 258-287, 2014.

WANG S, DAI Y, FUKUOKA T, YAMANAKA H, KOBAYASHI K, OBATA K, CUI X, TOMINAGA M, NOGUCHI K: Phospholipase $\mathrm{C}$ and protein kinase A mediate bradykinin sensitization of TRPA1: a molecular mechanism of inflammatory pain. Brain 131: 1241-1251, 2008a.

WANG YY, CHANG RB, WATERS HN, MCKEMY DD, LIMAN ER: The nociceptor ion channel TRPA1 is potentiated and inactivated by permeating calcium ions. J Biol Chem 283: 32691-32703, 2008b.

YIN K, BAILLIE GJ, VETTER I: Neuronal cell lines as model dorsal root ganglion neurons: A transcriptomic comparison. Mol Pain 12: 2016.

ZHANG X, HUANG J, MCNAUGHTON PA: NGF rapidly increases membrane expression of TRPV1 heat-gated ion channels. EMBO J 24: 4211-4223, 2005.

ZHANG X, LI L, MCNAUGHTON PA: Proinflammatory mediators modulate the heat-activated ion channel TRPV1 via the scaffolding protein AKAP79/150. Neuron 59: 450-461, 2008.

ZUBCEVIC L, HERZIK MA JR, CHUNG BC, LIU Z, LANDER GC, LEE SY: Cryo-electron microscopy structure of the TRPV2 ion channel. Nat Struct Mol Biol 23: 180-186, 2016.

ZURBORG S, YURGIONAS B, JIRA JA, CASPANI O, HEPPENSTALL PA: Direct activation of the ion channel TRPA1 by Ca2+. Nat Neurosci 10: 277-279, 2007.

ZYGMUNT PM, HOGESTATT ED: Trpa1. Handb Exp Pharmacol 222: 583-630, 2014. 